\title{
Emerging Significance of Sustainability Accounting and Reporting In India - A Conceptual Study
}

\section{Suprita Palit ${ }^{\star}$}

Department of Business Administration, Academy of Management and Information Technology, Bhubaneswar, Odisha, India

*Corresponding author: Suprita Palit, Department of Business Administration, Academy of Management Information Technology, Bhubaneswar, Odisha, India, Tel: 9078823990; E-mail: palit077@gmail.com

Received date: Jul 31, 2018; Accepted date: Sep 24, 2018; Published date: Oct 01, 2018

Copyright: (C) 2018 Suprita P. This is an open-access article distributed under the terms of the Creative Commons Attribution License, which permits unrestricted use, distribution, and reproduction in any medium, provided the original author and source are credited.

\begin{abstract}
The challenge of sustainable development is an important aspect in today's business arena. Linkage between corporate success and sustainability aspects of business has been established. In India, sustainability reporting by companies is gaining a lot of importance over the years. Even though leading standards such as Global Reporting Initiative (GRI) have made significant advancements in setting out the types of information that companies should publicly disclose, sustainability reports should be placed in a system that can effectively utilize the information and cause companies to change their policies and practices. This study discusses the benefits of sustainability reporting, the hindrances faced in its development and its status in India.
\end{abstract}

Keywords: Sustainability accounting; Sustainability reporting; Company performance; Economy; Society; Environment

\section{Introduction}

The changing global business environments have forced businesses to look beyond financial performance. The importance of integrating environmental and social issues within the business strategy has been realized by companies. Sustainability Accounting and Sustainability Reporting are relatively new concepts but have a great bearing on the performance of companies as a whole.

Sustainability accounting is considered as a sub category of financial accounting that focuses on the disclosure of non-financial information about a firm's performance to external parties such as investors, creditors, government and other authorities. It differs from Financial Accounting as it deals with economic, social and environmental performance in such a way those suppliers, government, employees and customers. This is done with the help of sustainability reporting, corporate social responsibility and non-financial reporting. The motto of sustainability accounting is 3Ps - People, Planet and Profits.

Sustainability reporting is a method in sustainability accounting. It deals with the preparation of a sustainable report which includes the goals, vision and missions of the organization. It conveys how the organization wants to contribute to the economy, society and environment and its commitment towards their development. It can be utilized by stakeholders like investors, government etc. to understand the organization's values.

The major providers of sustainability reporting guidance include:

- GRI (GRI's Sustainability Reporting Standards)

- The Organization for Economic Co-operation and Development (OECD Guidelines for Multinational Enterprises)

- The United Nations Global Compact (The communication on progress)

- The International Organization for Standardization (IS26000, International Standard for Social Responsibility).

\section{Objectives of the Study}

- To study the significance of Sustainability Accounting (SA) and Sustainability Reporting (SR) practices.

- To analyze the present scenario of Sustainability accounting and reporting practices in India.

- To assess the status of the regulatory framework regarding sustainability reporting in India.

\section{Literature Review}

According to Learn, n.d sustainability is divided into three dimensions:

- Environmental factors that deal with natural resources like water, energy, greenhouse gases etc.

- Social factors which include human rights, public policies, social safety and anti-corruption.

- Economic factors which focus on accounting value of stakeholders, economic and financial performance [1].

Buritt assessed the future of sustainability accounting and reporting and stated that the development of sustainability accounting and reporting should be oriented more towards management decision making. According to them managerial decision making and raising awareness could contribute to the development of sustainability accounting and reporting [2].

Mitra focused on the Sustainability Reporting Practices in India and analyzed the factors that slowed down the pace of development of this concept in India. Lack of knowledge among the leaders and managerial departments on this issue was attributed as the major hurdle in its growth. It was also pointed out that there is no legal requirement to produce sustainability reports and the demand of such information by stakeholders was also less [3].

Aggrawal presented various related theories establishing the relationship between corporate sustainability and financial performance. The three major theories cited are Legitimacy Theory, 
Stakeholder Theory and Agency Theory which suggest that companies should incorporate sustainability in their core strategic goals and disclose their sustainability performance in a proper sustainability report [4].

Bhalla and Bansal analyzed the economic aspect of sustainability reporting and have explained that economic indicators are not only expressed in monetary terms .The economic sustainability reports prepared by some Indian companies like Reliance Industries, TCS, Wipro etc. Also reflect how economic resources are used by the organizations to fulfill social obligations and how it benefits the organization and the society as a whole [5].

Godha and Jain examined the development in the Indian Regulatory environment for sustainability reporting and the status of the sustainability reporting practice of Indian companies as per the GRI reporting framework. It was stated that the number of large scale companies submitting reports as per GRI has increased over the years in comparison to small and medium enterprises and Indian multinational companies [6].

Jadhav et al. provided an insight into the sustainability reporting practices in India. According to them, large Indian companies have started to establish a clear link between sustainability and risk management .A trend of including sustainability elements as part of internal audit was also observed [7].

Rajan in his study of the significance and benefits of sustainability accounting and reporting has stated that as the concept is relatively new, companies require help and assistance in creating such reports and organizations like GRI provide the same. Sustainability accounting is still developing and the main challenge associated with it is the availability of accurate data for the same [8].

\section{Benefits of sustainability reporting}

Sustainability reporting benefits a business organization by:

- Improving company image and brand loyalty. It helps the company to maintain the reputation it has already developed. Also, it helps a company to overcome negative publicity, if any, received by it.

- Playing an important role in attracting and retaining employees as they become aware about how the companies they work for takes steps for their benefits.

- Leading to increased understanding of risks and opportunities and helps the companies seize opportunities to improve operations are mitigate risks that they have identified in relation to sustainability.

- Enabling external stakeholders to understand the organizations true value and tangible and intangible assets.

- Helping a company to incorporate its sustainability vision and strategy in its overall goals and ensuring their adherence.

- Enabling it to streamline its processes, reduce costs and improve efficiency $[9,10]$.

\section{Barriers to sustainability reporting}

Sustainability reporting in India faces the following barriers:

- There is no proper reporting standards and framework present in India with regard to it.

- It requires a lot of cost, time and expertise which small organizations find difficult to afford.
- Lack of knowledge about its benefits and importance among the business organizations.

- Fear of risking credibility and reputation.

- Fear of getting misinterpreted.

- Lack of proper training and education of management and employees responsible for preparing the report.

- Getting reliable and accurate data is difficult.

- There is the perception that stakeholders and investors do not read sustainability reports [11].

\section{Regulatory framework for sustainability reporting in India}

Currently there is no regulation that makes sustainability reporting in India mandatory. However, provisions have been incorporated under various legislations making it compulsory for business organizations to report on environmental matters specified therein.

Section 217 of the Companies Act 1956 stipulates that the Board of Directors Report should contain information on conservation of energy.

The Institute of Chartered Accountants of India (ICAI) has set up the ICAI- Accounting Research Foundation (ICAI-ARF) which has undertaken a special project to suggest a suitable framework for sustainability reporting for Indian companies. It is compulsory for the companies to report on social, environmental and economic initiatives. A committee is being formed for the framework for standardizing the disclosures related to sustainability reporting. Sustainability reporting has become mandatory for Indian companies that are planning to be listed abroad.

Apart from this various provisions in The Environment (Protection) Act, 1986 and The Factories Act, 1948 has either made it mandatory or desirable to furnish reports concerning the protection of environment, labour force, safety of employees etc. Various voluntary standards have come up with voluntary guidelines so that business organizations can make their value creating operations sustainable.

\section{Sustainability reporting practices in Indian companies}

Companies in India have a choice with regard to sustainability reporting and make a sustainability risk analysis only when they are prepared for it. As sustainability disclosures are voluntary, most of the companies do not opt for it. For example, even though the Indian Pharmaceutical Industry has a large manufacturing base in India, companies do not seem to have separate sustainability reports. However, companies in certain sectors like Metals and Mining, Oil and Gas, and Construction related activities have adopted a separate sustainability reporting practice because companies in these sectors are mandatorily required to conduct an Environment Impact Assessment and find it easier to make the requisite disclosures. Power companies are amongst the highest consumers of non-renewable resources and should be more responsible for disclosures on sustainability but most of them fail to do so. Only a few financial services companies report on sustainability. However with the increase in awareness of the benefits of sustainability reporting, more and more companies are taking up the disclosure requirement $[12,13]$.

\section{Recommendations}

- Building awareness that the process of reporting is important in achieving the long term strategic goals of the companies. 
Citation: Suprita P (2018) Emerging Significance of Sustainability Accounting and Reporting In India - A Conceptual Study. Int J Account Res 6: 180. doi: $10.35248 / 2472-114 X .18 .6 .180$

Page 3 of 3

- Educating the staff concerned in preparation of the report so that they have a clear idea about its objectives

- Necessary steps should be taken to collect reliable and accurate data for the preparation of the report.

\section{Conclusion}

Sustainability reporting in India is still in its nascent stage. Currently, except for some high performing large companies, many organizations have not started using GRI reporting framework effectively. Reliability and accuracy of the data is also a major issue. In order to face the global competition, Indian companies should adopt the GRI based sustainability reporting practices on a larger scale because sustainability reporting has now become a standard practice for global companies.

\section{References}

1. http://www.landlearnsw.org.au/sustainability/what-is-sustainability

2. Burritt RL, Schalteggar S (2010) Sustainability Accounting and Reporting: Fad or Trend? Accounting Auditing Accountability J 23: 829-846.

3. Mitra PK (2012) Sustainability Reporting Practices in India: Its problems and prospects. Int J Mark Financ Serv Manage Res 1: 109-115.
4. Aggarwal P (2013) Impact of Sustainability Performance of Company on its Financial Performance: A Study of Listed Indian Companies. Global J Manage Bus Res Financ 13: 61-70.

5. Bhalla R, Bansal SK (2014) Corporate Sustainability Reporting: A Study of Economic Sustainability Aspect by Selected Indian Corporations. Int $J$ Curr Res Acad Rev 2: 37-46.

6. Godha A, Jain P (2015) Sustainability Reporting Trend in Indian Companies as per GRI Framework: A Comparative Study. South Asian J Bus Manage cases 4: 62-73.

7. Jadhav D, Jain R, Umbarkar S (2015) The State of Sustainability Reporting in India. ASM'S Int E-Journalon Ongoing Res Manage IT, pp: 336-343.

8. Rajan V (2016) Reporting With Reputation and Returns-The Emerging Significance of Sustainability Accounting. Annual J SCMS Pune 4: 55-66.

9. Millar M (2018) The Pros and Cons of Sustainability Reporting.

10. Venkateswara KS, Rama DV (2015) Sustainability Reporting Practices in India: Challenges and Prospects. Twelfth AIMS International Conference on Management.

11. http://www.giz.de/en/downloads/giz-2012-sustainable-reporting-indiaen.pdf

12. www.globalreporting.org

13. www.icsi.edu 